\title{
Preparation and Proton Exchange Properties of GO Grafting modified Cross-linked Membranes
}

\author{
Zhengping Zhao ${ }^{1,2, *}$, Chenyu Pan ${ }^{2}$, Guojun Jiang ${ }^{1}$, Mingqiang Zhong ${ }^{2}$ and Benhua Fei ${ }^{3}$ \\ ${ }^{1}$ Zhijiang College, Zhejiang University of Technology, Hangzhou 310014, China \\ ${ }^{2}$ College of Materials Science and Engineering, Zhejiang University of Technology, Hangzhou \\ 310014, China \\ ${ }^{3}$ International Center for Bamboo and Rattan, Beijing 100102, China \\ "E-mail: sjzhaolei@163.com
}

doi: $10.20964 / 2018.08 .11$

Received: 10 April 2018 / Accepted: 22 May 2018 / Published: 5 July 2018

\begin{abstract}
The cross-linked membranes were prepared with DS 68\% SPEEK and epoxy resin. Sulfonated graphite oxide was grafted into SPEEK main bonds to study the sulfonic acid groups on the impact of proton exchange properties. Using solartron electrochemical testing system to analysize the conducting proton properties of membranes. It is found that to achieve the same proton conductivity, the graft sulfonated graphene oxide content in the membrane need to be high. When the proton conductivity reaches a certain value and continue to increase the content of sulfonated graphene oxide, there will be a 'blocking effect' which due to the proton conductivity reduce instead. The cross-linked of epoxy resin has part of the effects on the proton conductivity of graft membrane. The highest value reached $5.2 \times 10^{-2} \mathrm{~S} \cdot \mathrm{cm}^{-1}$. But it is still falling with the increase content of epoxy resin. Introduction of the sulfonic acid groups provide springboard for proton exchange membrane conduction protons. The interpenetrating network structures increases the chains winding and piling to increase the density of the membranes. And the water swelling resistance has a good improvement. The structure will not be loose at high temperature, and guide protons performance is not affected.
\end{abstract}

Keywords: Electrochemical properties, SPEEK, membranes, grafting

\section{$\underline{\text { FULL TEXT }}$}

(C) 2018 The Authors. Published by ESG (www.electrochemsci.org). This article is an open access article distributed under the terms and conditions of the Creative Commons Attribution license (http://creativecommons.org/licenses/by/4.0/). 